\title{
Determination of germ tube, phospholipase, and proteinase production by bloodstream isolates of Candida albicans
}

\author{
Antonella Souza Mattei ${ }^{[1]}$, Sydney Hartz Alves ${ }^{[2]}$, Cecília Bittencourt Severo ${ }^{[3]}$, \\ Luciana da Silva Guazzelli[ ${ }^{[3]}$, Flávio de Mattos Oliveira ${ }^{[3]}$ and Luiz Carlos Severo[ ${ }^{[4]}$
}

[1]. Programa de Pós Graduação em Ciências Pneumológicas, Universidade Federal do Rio Grande do Sul, Porto Alegre, RS. [2]. Departamento de Microbiologia e Parasitologia, Universidade Federal de Santa Maria, Santa Maria, RS. [3]. Laboratório de Micologia, Santa Casa de Misericórdia de Porto Alegre, Porto Alegre, RS. [4]. Faculdade de Medicina, Universidade Federal do Rio Grande do Sul, Porto Alegre, RS.

\begin{abstract}
Introduction: Candida albicans is a commensal and opportunistic agent that causes infection in immunocompromised individuals. Several attributes contribute to the virulence and pathogenicity of this yeast, including the production of germ tubes (GTs) and extracellular hydrolytic enzymes, particularly phospholipase and proteinase. This study aimed to investigate GT production and phospholipase and proteinase activities in bloodstream isolates of C. albicans. Methods: One hundred fifty-three C. albicans isolates were obtained from blood samples and analyzed for GT, phospholipase, and proteinase production. The assays were performed in duplicate in egg yolk medium containing bovine serum albumin and human serum. Results: Detectable amounts of proteinase were produced by $97 \%$ of the isolates, and $78 \%$ of the isolates produced phospholipase. GTs were produced by $95 \%$ of the isolates. A majority of the isolates exhibited low levels of phospholipase production and high levels of proteinase production. Conclusions: Bloodstream isolates of C. albicans produce virulence factors such as GT and hydrolytic enzymes that enable them to cause infection under favorable conditions.
\end{abstract}

Keywords: Virulence. Germ tube. Phospholipase. Proteinase. Candida albicans. Candidemia.

\section{INTRODUCTION}

Candida albicans is a common colonizer of human skin and mucosal surfaces. The balance between colonization and candidiasis depends on changes in the expression of virulence factors in response to environmental changes and the competence of the host immune system ${ }^{1}$.

Several virulence factors of $C$. albicans have been discovered or proposed, including adhesion factors, hyphal formation, germ tubes (GTs), phenotypic diversity, and the production of extracellular hydrolytic enzymes such as phospholipases and proteinases $^{2-6}$.

Hydrolytic enzymes destroy or disorganize elements of host cell membranes, leading to membrane dysfunction and/ or physical disruption. Phospholipases act by invading host cells, causing tissue damage, rupturing the epithelial cell membranes, and allowing hyphae to penetrate the cytoplasm. Proteinase production increases the ability of certain organisms to colonize and penetrate host tissue, deceive the host immune

\footnotetext{
Address to: Dra. Antonella Souza Mattei. Laboratório de Micologia/Hospital Santa Rita. Rua Professor Annes Dias 285, 90020-090 Porto Alegre, RS, Brasil. Phone 5551 3214-8409; 5551 3214-8435

e-mail: antonella.mattei@hotmail.com

Received 28 February 2013

Accepted 16 May 2013
}

system, and disrupt a significant number of proteins important for immunity such as immunoglobulins, complement proteins, and cytokines ${ }^{5,7-9}$. Yeast can be induced to produce GTs, which develop into mycelia. This morphological transition can be induced by changes in a variety of environmental factors and by blocking the host immune response ${ }^{10}$.

Because of the increasing incidence of invasive C. albicans infections, interest in their virulence factors has increased. This avenue of research may help to establish strategies for the prevention and control of candidiasis and identify possible targets for the development of new therapeutic interventions ${ }^{7,11}$. However, studies of the relationship between GT production and hydrolytic enzyme activity in bloodstream isolates are scarce ${ }^{2,12}$.

Therefore, this study aimed to investigate the known virulence factors, including phospholipase and proteinase activity and GT production, in bloodstream isolates of C. albicans in vitro.

\section{METHODS}

One hundred fifty-three human isolates of $C$. albicans were obtained from blood samples between 1999 and 2009, and the yeast was identified using the ID 32C assay (BioMérieux, MarcyI'Etoile, France); isolates were stored at $-20^{\circ} \mathrm{C}$ in a freezer at a mycology laboratory (Santa Casa de Porto Alegre, Rio Grande do Sul, Brazil). The isolates were analyzed for GT, phospholipase, and proteinase production. The standard strain of C. albicans, ATCC 28367 (American Type Culture Collection, Rockville, MD, Manassas, USA), was included in the experiments as a control. 
TABLE 1 - Hydrolytic enzyme activity for 153 bloodstream Candida albicans isolates.

\begin{tabular}{|c|c|c|c|c|c|c|}
\hline & & \multicolumn{5}{|c|}{ Phospholipase (n) } \\
\hline \multicolumn{2}{|c|}{ Production of extracellular hydrolytic enzymes $(\mathrm{Pz})$} & $(0.35-0.5)$ & $(0.51-0.74)$ & $(0.75-0.99)$ & (1) & (n) \\
\hline \multirow{2}{*}{ 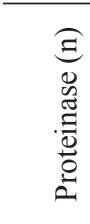 } & High $(0.35-0.5)$ & 10 & 19 & 34 & 18 & 81 \\
\hline & Moderate (0.51-0.74) & 4 & 16 & 24 & 12 & 56 \\
\hline \multicolumn{2}{|c|}{ Total (n) } & 17 & 38 & 65 & 33 & 153 \\
\hline
\end{tabular}

Pz: activity zone for phospholipase and proteinase.

The Candida albicans inoculum was prepared from stock cultures, incubated for $24 \mathrm{~h}$ at $37^{\circ} \mathrm{C}$ in Sabouraud dextrose agar, and standardized according to the $0.5 \mathrm{McF}$ arland turbidity range using a densitometer (BioMérieux).

The isolates were screened for their extracellular phospholipase activity by growing them on egg yolk medium and measuring the diameter of the zone of precipitation as previously described by Vidotto et al. ${ }^{8}$. The egg yolk medium consisted of $22.5 \mathrm{~g}$ of malt agar, $29.2 \mathrm{~g}$ of $\mathrm{NaCl}, 0.28 \mathrm{~g}$ of $\mathrm{CaCl}_{2}$, and $10 \%$ sterile egg yolk. Extracellular phospholipase activity was detected by inoculating $10-\mu \mathrm{L}$ aliquots of $C$. albicans suspensions (approximately $1 \times 10^{8}$ cells $/ \mathrm{mL}$ ) into wells punched through the surface of the egg yolk medium. The diameter of the precipitation zone around the well was measured after incubation at $37^{\circ} \mathrm{C}$ for 6 days. Phospholipase activity (Pz value) was determined as the ratio of the diameter of the colony to the total diameter of the zone of precipitation.

The determination of protease production was performed in agar containing bovine serum albumin, as previously described by Mohan \& Ballal $^{2}$. A solution was prepared by dissolving $11.7 \mathrm{~g}$ of yeast carbon base, $0.1 \mathrm{~g}$ of yeast extract, and $2 \mathrm{~g}$ of bovine serum albumin in $200 \mathrm{~mL}$ of distilled water. The solution was sterilized by filtration and added to a previously sterilized stock solution of $16 \mathrm{~g}$ of agar-agar in $800 \mathrm{~mL}$ of distilled water. After inoculation, plates were incubated at $37^{\circ} \mathrm{C}$, and the results were recorded after 6 days of incubation. Enzyme activity was measured as the diameter of the lytic area surrounding the growth area on the serum medium.

The Pz value was determined as the ratio of the diameter of the colony to the total diameter of the colony plus the precipitation zone, and it was scored and categorized as follows: $\mathrm{Pz}$ value $=1$ (negative); Pz value $=0.75-0.9$ (low producers); Pz value $=0.51-0.74$ (moderate producers); and $\mathrm{Pz}$ value $=0.35$ 0.5 (high producers). The assay was performed in duplicate, and the enzyme activity values were recorded as the average of the two measurements.

Germ tubes production is defined as a filamentous outgrowth from a blastoconidium at least twice as long as the parent cell without constriction at the junction. Isolated colonies of C. albicans were inoculated in glass tubes with $1 \mathrm{~mL}$ of human serum and incubated at $37^{\circ} \mathrm{C}$ for $2 \mathrm{~h}$. A drop of the inoculum was then placed on a clean microscope slide, and a coverslip was placed on the slide. Wet mount preparations were examined under the objective lens of a microscope ( $\times 40$ magnification), and tests were performed in duplicate.

\section{Ethical considerations}

The hospital (Santa Casa de Porto Alegre, Rio Grande do Sul, Brazil) ethics committee approved this study.

\section{RESULTS}

Phospholipase activity was detected for 78\% (120/153) of C. albicans isolates, and proteinase activity was detected for $97 \%(148 / 153)$ of isolates.

The mean Pz value was 0.79 (range, 0.48-1.00). The average value for proteinase activity was 0.71 (range, $0.49-1.00$ ).

Isolates were categorized by their levels of phospholipase and proteinase production. The activity of these enzymes is shown in Table 1. A majority of $C$. albicans isolates with enzymatic activity displayed high proteinase activity and low phospholipase activity. Of the isolates studied, $73 \%$ produced both phospholipase and proteinase.

Germ tubes induction was positive in 95\% (146/153) of bloodstream C. albicans isolates. The associations of GT production with phospholipase and proteinase activity are described in Table 2.

TABLE 2 - Virulence factor (GT, phospholipase, and proteinase production) associations in bloodstream isolates of Candida albicans.

\begin{tabular}{lcc}
\hline Virulence factor associations & Number & Percentage \\
\hline Phospholipase + GT & 5 & 3.0 \\
Proteinase + GT & 33 & 22.0 \\
Phospholipase + proteinase & 7 & 5.0 \\
Phospholipase + proteinase + GT & 108 & 70.0 \\
\hline Total & 153 & 100.0 \\
\hline
\end{tabular}

GT: germ tube. 


\section{DISCUSSION}

Yeasts of the genus Candida continue to be among the most important etiologic agents of nosocomial infections. Deep-seated candidemia, the occurrence of which has considerably increased, is most commonly observed in ICU patients with indwelling catheters, individuals receiving oncological treatment, organ transplant recipients, or other immunocompromised individuals subjected to heavy therapeutic protocols $\mathrm{s}^{2,13}$.

Although many studies have investigated the exoenzyme activity of Candida spp. isolated from mucosal surfaces s $^{3,7-9,12,14,15}$, few have investigated bloodstream isolates ${ }^{2}, 12$. The virulence of Candida spp. is believed to be caused by the combination of several factors ${ }^{12}$, including its ability to colonize a variety of different anatomic sites ${ }^{7}$.

The phospholipases and proteinases of $C$. albicans are considered important virulence factors, and the absence or decreased expression of these enzymes may indicate reduced virulence for some Candida species $^{2}$.

In our study, 78 and $97 \%$ of the isolates displayed phospholipase and proteinase activity, respectively. Mohan \& Ballal $^{2}$ found a similar percentage of phospholipase activity; however, only $44 \%$ of the isolates that they studied exhibited proteinase activity, suggesting that the isolates used in this study were comparatively more virulent.

Few studies have investigated phospholipase and proteinase production simultaneously in the same strains. In the present study, $73 \%$ of the isolates produced both phospholipase and proteinase, which is in concordance with the results obtained by D`Eça Júnior et al. ${ }^{7}$ and Kantarcioglu \& Yucel ${ }^{15}$, who observed concurrent production in 60 and $93 \%$ of C. albicans isolates, respectively. However, the isolates used in those studies were isolated from different anatomic sites.

In another similar study, measures of enzymatic activity indicated that all C. albicans isolates were pathogenic ${ }^{2}$. However, the present study identified no hydrolytic enzyme activity in $38 \%$ of the isolates.

Germ tubes production was observed for $95 \%$ of the isolates. High levels of phospholipase production were observed in 13 of the GT-positive isolates. Vidotto et al. ${ }^{12}$ described a correlation between high phospholipase activity and GT production in oral isolates, which suggests that these virulence factors are necessary for C. albicans colonization and infection of the oral cavity. It is possible that high levels of phospholipase activity and GT production can facilitate penetration through the mucosa because phospholipase activity is particularly concentrated in hyphal tips.

Ghannoum $^{4}$ and D'Eça Júnior et al. ${ }^{7}$ suggested that the quantity of phospholipase produced by $C$. albicans varies with each specific isolate, and it is correlated with the site of infection.

In our study, bloodstream isolates of C. albicans produced extracellular phospholipase and proteinase. In general, bloodstream isolates are known to produce much higher levels of phospholipase and proteinase than wound or urine isolates ${ }^{4,15}$.

Bloodstream isolates of $C$. albicans produce virulence factors, including GT and hydrolytic enzymes, making them capable of causing infection under favorable conditions.

\section{FINANCIAL SUPPORT}

Coordenação de Aperfeiçoamento de Pessoal de Nível Superior (CAPES).

\section{CONFLICT OF INTEREST}

The authors declare that there is no conflict of interest.

\section{REFERENCES}

1. Ibrahim A, Mirbod F, Filler S, Banno Y, Cole G, Kitajima Y, et al. Evidence implicating phospholipase as a virulence factor of Candida albicans. Infect Immun 1995; 63:1993-1998.

2. Mohan V, Ballal M. Proteinase and phospholipase activity as virulence factors in Candida species isolated from blood. Rev Iberoam Micol 2008; 25:208-210

3. Scheid L, Mario D, Lopes P, Loreto E, Linares C, Santurio J, et al. Candida dubliniensis does not show phospholipase activity: true or false? Rev Soc Bras Med Tropical 2010; 43:205-206.

4. Ghannoum M. Potential Role of Phospholipases in Virulence and Fungal Pathogenesis. Clin Microbiol Rev 2000; 13:122-143.

5. Schulze J, Sonnenborn U. Yeasts in the Gut: From Commensals to Infectious Agents. Dtsch Arztebl Int 2009; 106:837-842.

6. Brand A. Hyphal Growth in Human Fungal Pathogens and Its Role in Virulence. Int J Microbiol 2012; 2012:517-529.

7. D’Eça Jr A, Silva A, Rosa F, Monteiro S, Figueiredo P, Monteiro C. In vitro differential activity of phospholipases and acid proteinases of clinical isolates of Candida. Rev Soc Bras Med Trop 2011; 44:334-338.

8. Vidotto V, Pontón J, Aoki S, Quindós G, Mantoan B, Pugliese A, et al. Differences in extracellular enzymatic activity between Candida dubliniensis and Candida albicans isolates. Rev Iberoam Micol 2004; 21:70-74.

9. Ombrella A, Racca L, Ramos L. Actividades proteinasa y fosfolipasa de aislamientos de Candida albicans provenientes de secreciones vaginales con distintos valores de $\mathrm{pH}$. Rev Iberoam Micol 2008; 25:12-16.

10. Kim D, Shin W, Lee K, Kim K, Park J, Koh C. Rapid differentiation of Candida albicans from other Candida species using its unique germ tube formation at $39^{\circ} \mathrm{C}$. Yeast 2002; 19:957-962.

11. Rorig KCO, Colacite J, Abegg MA. Production of virulence factors in vitro by pathogenic species of the genus Candida. Rev Soc Bras Med Trop 2009; 42:225-227.

12. Vidotto V, Koga-Ito C, Milano R, Fianchino B, Pontón J. Correlation between germ tube production, phospholipase activity and serotype distribution in Candida albicans. Rev Iberoam Micol 1999; 16:208-210.

13. Giri S, Kindo A. A review of Candida species causing blood stream infection. Indian J. Med. Microbiol 2012; 30:270-278.

14. Marcos-Arias C., Eras E, Madariaga L, Aguirre J, Quindós G. Phospholipase and proteinase activities of Candida isolates from denture wearers. Mycoses 2009; 54:e10-e16.

15. Kantarcioglu A, Yucel A. Phospholipase and protease activities in clinical Candida isolates with reference to the sources of strains. Mycoses 2002; 45:160-165. 